\title{
Cross-linking of Hydroxyl-terminated Polyols with Triethyleneglycol Diglycidyl Ether: An Alternative to Toxic Isocyanates
}

\author{
Eleftheria Dossi, ${ }^{[a]}$ Jacqueline Akhavan, ${ }^{[a]}$ Sally E. Gaulter, ${ }^{[a]}$ Richard G. Williams ${ }^{[b]}$ and William J. \\ Doe ${ }^{[c]}$
}

[a] Centre for Defence Chemistry, Cranfield University, Defence Academy of United Kingdom, Shrivenham, SN6 8LA, UK e.dossi@cranfield.ac.uk, j.akhavan@cranfield.ac.uk, s.e.gaulter@cranfield.ac.uk

[b] Royal Australian Air Force, Department of Defence, Penrith, NSW 2750, Australia Richard Williams richard.williams1@defence.gov.au

[c] DE\&S, DESG Graduate Office, MoD, Abbey Wood, Bristol BS34 8JH, UK Williamjamesdoe@hotmail.com

Supporting information for this article is available on the WWW under https://doi.org/

\begin{abstract}
Isocyanates are highly reactive and toxic substances with severe health effects. Certain diisocyanates are restricted under

REACH - The European Regulation on Registration, Evaluation, Authorisation and Restriction of Chemicals. Triethyleneglycol diglycidyl ether (TEGDGE) was used as an alternative to toxic isocyanates for the cross-linking of hydroxyl-terminated pre-polymers at $70^{\circ} \mathrm{C}$. The effect of three curing accelerators was determined while following the reaction kinetics by ${ }^{1} \mathrm{H}-\mathrm{NMR}$ spectroscopy and differential scanning calorimetry (DSC). Polybutadiene (Poly BD R45HT-LO) and acrylic ester (HyTemp 4454) successfully crosslinked in 7-10 days to produce thermally stable networks with low glass transition temperatures, as observed by DSC. Pre-aging the polybutadiene resin promoted cross-linking with TEGDGE. Four energetic compositions were then prepared using cyclotrimethylenetrinitramine (RDX) and pentaerythritoltetranitrate (PETN) as fillers, and polybutadiene (Poly BD R45HT-LO) and acrylic ester (HyTemp 4454) as binders. Both binders successfully crosslinked with TEGDGE in the presence of RDX and PETN, but only PETN was found to be chemically compatible with the cross-linked polymers. These results show that TEGDGE is suitable as a replacement for toxic isocyanates for the cross-linking of hydroxylterminated polyols.
\end{abstract}

\section{Introduction}

Isocyanates are used in the polymer industry to manufacture polyurethanes with diverse applications, including foams, varnishes, low-density elastomers (rubbers), and textiles. Hydroxyl-terminated polyols form polyurethanes $[1,2]$ that contain urethane linkages with di-isocyanates and/or tri-isocyanates as the preferred cross-linkers [3-5]. Although isocyanates are effective cross-linkers for polyols such as polybutadienes (HTPB), one major drawback is the significant health hazards posed by these compounds, highlighted by the Bhopal disaster of $1984[6,7]$. There is a large body of literature on the health effects of isocyanates, which are classified as highly toxic and also carcinogenic [8-11]. REACH regulation of the European Union, adopted to improve the protection of human health and the environment from the risks that can be posed by chemicals, has introduced restrictions on the manufacture, placing on the market and use of certain diisocyanates [12]. A brief assessment pertaining to toluene diisocyanate (TDI), highlights several areas of concern: TDI is considered highly toxic by inhalation (Vapour pressure $1.33 \mathrm{~Pa}$ at $25^{\circ} \mathrm{C}$ ), mildly toxic via ingestion, and dermal (skin) contact can result in inflammation, eczema and dermatitis [8]. Additionally inhalation and dermal contact with TDI can cause immune system sensitization and asthma, even at very low exposures. Long term exposure to TDI can result in significantly reduced lung function, whilst acute exposure to high concentrations can result in coma, pulmonary oedema or severe respiratory distress; any of which can result in death. Furthermore, isocyanates are manufactured though the reaction of phosgene and a corresponding primary amine (in this case toluene diamine) [9]. Phosgene is a highly toxic pulmonary irritant and as such its use should also be reduced where possible. TDI is also considered a potential carcinogen in humans by the World Health Organisation [8], though a consensus on its carcinogenetic properties has not been reached. When ingested by rats, TDI hydrolyzes at aqueous tissue surfaces creating toluene diamine (TDA), a mutagen and rodent carcinogen [13] though its properties as a carcinogen in humans has been questioned [14]. It is noted that much of these toxicological properties are 
characteristic of the $-\mathrm{N}=\mathrm{C}=\mathrm{O}$ functional group, and thus likely to be pertinent for most isocyanates [11] .

More recently, non-isocyanate polyurethanes formed via a cyclocarbonate and an amine reaction [15] have been used to manufacture hard coatings and foams with properties comparable to isocyanate polyurethanes [16-18]. However the presence of amines is incompatible with many energetics [19]. Polyethers can be used as an alternative to polyurethanes, and they are formed by cross-linking epoxy and hydroxyl groups [20]. However the use of polyethers in energetic systems is limited [21].

Hydroxyl-terminated pre-polymers react with di-epoxy and multiepoxy cross-linkers in the presence of a catalyst, and such crosslinked polymers are compatible with energetic materials. The side units [22] formed during the synthesis of the pre-polymers can be hydroxyl and/or epoxy groups, which then contribute to the formation of the polyether network [21]. Energetic substituted polyphosphazenes with pendant groups bearing hydroxyl side units can also be cured with diglycidyl ethers $[23,24]$ to produce thermally stable polyethers that are compatible with energetics. In cured polyether networks, the extra hydroxyl groups derived from the opened epoxy ring contribute to the formation of the threedimensional structure.

This paper shows that TEGDGE $[25,26]$ can be used as a replacement for highly toxic isocyanates. TEGDGE is a lower molecular weight analogue of polyethylene glycol diglycidyl ether which is classified as not a hazardous substance or mixture according to Regulation (EC) No 1272/2008 [27]. TEGDGE has a very low vapour pressure $0.08 \mathrm{~Pa}$ at $25^{\circ} \mathrm{C}$ comparing to highly volatile diisocyanates and it is listed as toxic chemical and unclassifiable as cancerogenic [28]. Initial experiments determined the ability of TEGDGE to cross-link with commercially available hydroxyl-terminated pre-polymers such as polytetramethylene ether glycol, polybutadiene, polyacrylic ester, linear polypropylene glycol, perfluoropolyether and epoxidised polybutadiene $[29,30]$. The successfully cross-linked polymers were then downselected and formulated with two energetic fillers: the nitramine cyclotrimethylenetrinitramine (known as RDX) and the nitrate ester pentaerythritoltetranitrate (known as PETN). Initial small-scale compatibility studies were undertaken using the cross-linked polymers and the energetic fillers before proceeding to medium-scale formulations, which were used for hazard testing.

\section{Experimental Section}

\section{Warning}

Small-scale and best safety practices (leather gloves, face shield) are strongly recommended for the handling of energetic fillers RDX and PETN and their formulations.

\section{Materials}

Sodium hydroxide, tetrabutylammonium bromide, triethyleneglycol, epichlorohydrin, scandium trifluoromethanesulfonate 2-ethylimidazol, and tributylamine were obtained from
Sigma Aldrich. Terathane 2000 (Invicta), HTPB R45M (Sartomer), Hytemp 4454 (Zeon Chemicals), Poly BD R45HT-LO (Sartomer), Polyol 12200N (Acclaim), Fluorolink E10/H (Solvay Solexis) and Liquiflex P (Krahn Petroflex) were available at Cranfield University. Poly BD R45HT-LO (Sartomer) was supplied by BAESystems Land, and Poly BD 605E (Cray Valley) and Poly BD 700E (Cray Valley) were supplied by AWE. The nitramine and nitrate ester were available at Cranfield University.

\section{Measurements}

NMR spectra were collected on a Bruker AVANCE III $400 \mathrm{MHz}$ NMR spectrometer fitted with a 5-mm BBFO broad band RF, running TopSpin analysis software. Differential scanning calorimetry (DSC) thermograms were recorded using Mettler DSC-1, DSC-30 and DSC-822 calorimeters. GPC analysis was carried out using a Viscotek VE1121 GPC solvent pump, a Kontron Instruments DEG-104 degasser, a Waters 717 Plus autosampler and a Waters 2414 refractive index detector set at $35^{\circ} \mathrm{C}$.

\section{Synthesis of TEGDGE}

Sodium hydroxide $(40.00 \mathrm{~g}, 1 \mathrm{~mol})$ in water $(50 \mathrm{ml})$, tetrabutylammonium bromide $(1.19 \mathrm{~g}, 7.40 \mathrm{mmol})$ and epichlorohydrin $(92.70,1 \mathrm{~mol})$ were all placed in a three-necked round-bottomed flask. The reaction mixture was stirred vigorously for $1 \mathrm{~h}$ and triethyleneglycol $(25.60 \mathrm{~g}, 0.17 \mathrm{~mol})$ was then added slowly at room temperature with further vigorous mechanical stirring for $3 \mathrm{~h}$. The reaction mixture was stirred at $40^{\circ} \mathrm{C}$ for at least $1 \mathrm{~h}$, allowed to cool and then filtered. The liquid phase was collected, dried overnight on sodium sulfate, and the excess epichlorohydrin was evaporated to leave a yellow-orange viscous liquid. ${ }^{1} \mathrm{H}-\mathrm{NMR}\left(400 \mathrm{MHz}, \mathrm{d}-\mathrm{CDCl}_{3}\right): \delta=4.00-3.40\left(\mathrm{~m}, 16 \mathrm{H}, \mathrm{CH}_{2}-\right.$ O), $3.15(\mathrm{~m}, 2 \mathrm{H}, \mathrm{CH}), 2.80$ and $2.62\left(2 \mathrm{~m}, 4 \mathrm{H}, \mathrm{CH}_{2}-\mathrm{CH}\right) ;{ }^{13} \mathrm{C}-\mathrm{NMR}$ $\left(\mathrm{d}-\mathrm{CDCl}_{3}\right): \delta=71.99\left(\mathrm{CH}_{2}-\mathrm{O}\right), 70.90,70.66$ and $70.63\left(\mathrm{CH}-\mathrm{CH}_{2}-\right.$ O), 50.81 ( $\mathrm{CH}$ ring) and $44.4 \mathrm{ppm}\left(\mathrm{CH}_{2}\right.$ ring); DSC $\left(10^{\circ} \mathrm{C} \mathrm{min}{ }^{-1}\right.$, $\left.\mathrm{N}_{2}\right) \max 331.5^{\circ} \mathrm{C}(\mathrm{dec})$; DSC $\left(10^{\circ} \mathrm{C} \mathrm{min}^{-1}, \mathrm{~N}_{2}\right) \mathrm{T}_{\mathrm{g}}=-80^{\circ} \mathrm{C}$.

\section{Curing of pre-polymers (P1-P10) with TEGDGE}

Samples (1.00-2.04 g) of hydroxyl-terminated pre-polymers $\mathrm{P} 1$ to P10 (Figure 1), with up to $1.74 \mathrm{meq}^{-1}$ of hydroxyl groups, were placed in glass vials. TEGDGE $(0.29-1.71 \mathrm{~g})$ was added to the polymers to provide pre-cure mixtures with $1: 3.5 \mathrm{w} / \mathrm{w}$ TEGDGE:pre-polymer stoichiometry. A curing accelerator $(0.1 \%$ $\mathrm{w} / \mathrm{w} 2$-ethylimidazole, $0.1 \% \mathrm{w} / \mathrm{w}$ tributylamine or 0.1 and $1 \% \mathrm{w} / \mathrm{w}$ scandium trifluoromethanesulfonate) was added to some of the formulations. If required, chloroform or ethyl acetate was added to facilitate mixing, and the solvent was then removed by rotary evaporation and by leaving the mixture under a high vacuum for $2 \mathrm{~h}$ at room temperature to drive off the last traces of solvent. The mixtures were then sealed and placed into a thermostatically controlled oven pre-set to $70^{\circ} \mathrm{C}$. The progress of curing was checked visually and by NMR and DSC at regular intervals during a period of 30 days. A small sample from each cured mixture was treated with chloroform- $\mathrm{d}$ for $1 \mathrm{~h}$ at room temperature to remove any excess of unreacted cross-linker. The soluble fractions in 
chloroform-d were characterised by ${ }^{1} \mathrm{H}-\mathrm{NMR}$ spectroscopy, whereas the insoluble gels were dried, weighed and then characterised by DSC.

\section{Formulating with energetic compounds}

\section{Compatibility tests using uncured $P 6$ and $P 10$ with energetic compounds RDX and PETN}

The energetic compound (10.00 mg) was placed into a $50-\mathrm{ml}$ nickel crucible before adding a solution of pre-polymer P6 in chloroform or P10 in ethyl acetate (explosive:pre-polymer ratio = $1: 1 \mathrm{w} / \mathrm{w})$. The mixture was stirred gently by hand using a bone/ceramic spatula to allow the solvent to evaporate under ambient conditions, leaving a dry mixture for small-scale compatibility tests (hazard testing and thermal stability testing).

\section{Formulation of P6 and P10 with energetic compounds RDX and PETN, and curing with TEGDGE}

Each $10.00 \mathrm{~g}$ batch comprised a 3.5:1 ratio of pre-polymer to TEGDGE and a 95:5 mixture of energetic compound to the prepolymer/TEGDGE mixture. We then placed $0.50 \mathrm{~g}$ of the mixture (0.39 $\mathrm{g}$ polymer and $0.11 \mathrm{~g}$ TEGDGE) into a $100 \mathrm{ml}$ round bottomed flask and added $10 \mathrm{ml}$ of solvent. The mixture was magnetically stirred for $16 \mathrm{~h}$ until all the reagents had dissolved. The energetic compound ( $9.50 \mathrm{~g}$ RDX or PETN) was weighed into a $250-\mathrm{ml}$ nickel crucible, and the pre-polymer solution was added. The mixture was then stirred gently by hand using a bone/ceramic spatula to allow the solvent to evaporate under ambient conditions, initially leaving a viscous liquid suspension, then a doughy residue, and finally a crumb-like mixture. The mixture was folded using a spatula throughout to ensure thorough and uniform mixing. After most of the solvent had evaporated, the mixture was placed in a vacuum desiccator for $16 \mathrm{~h}$ to drive off the remaining solvent. The formulation was then split into two $5.00 \mathrm{~g}$ batches, one placed in the oven at $70^{\circ} \mathrm{C}$ for curing and the other used for Energetic Materials Testing and Assessment Policy (EMTAP) [31] tests without curing.

\section{Results and Discussion}

\section{Curing pre-polymers with TEGDGE}

TEGDGE $[23,25]$ was successfully synthesised by reacting triethyleneglycol with a large excess of epichlorohydrin $(0.17: 1)$ in aqueous sodium hydroxide. The product $(30.45 \mathrm{~g}, 68.1 \%)$ was analysed by ${ }^{1} \mathrm{H}-\mathrm{NMR}$ and ${ }^{13} \mathrm{C}-\mathrm{NMR}$ spectroscopy. Samples $\mathrm{P} 1$ to P10 (Figure 1) containing 0.53-1.74 meq $\mathrm{g}^{-1}$ of terminal hydroxyl groups and with an average polymeric molecular weight of 1900
$11,220 \mathrm{~g} \mathrm{~mol}^{-1}$ were characterised by ${ }^{1} \mathrm{H}-\mathrm{NMR}$ spectroscopy in chloroform-d prior to the cross-linking experiments.

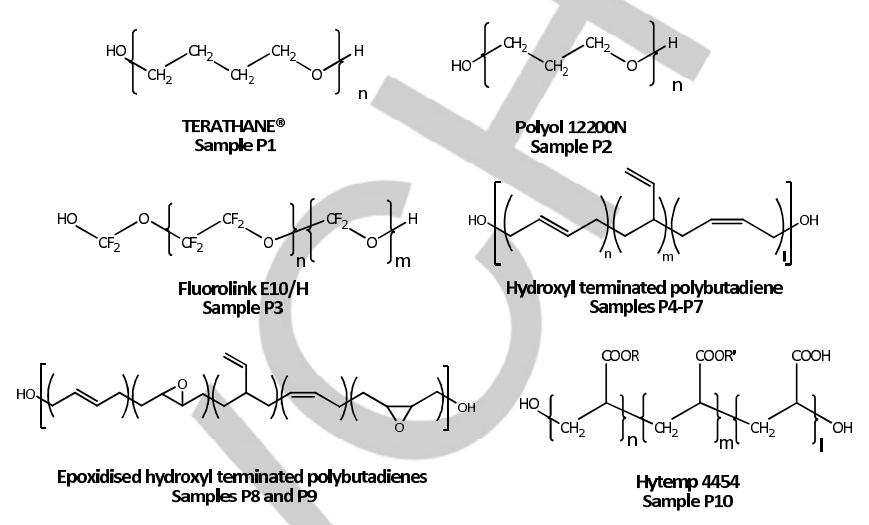

Figure 1. Chemical structures of pre-polymers P1-P10.

No solvent was required to mix the curing ingredients except for pre-polymer P10, which was dissolved in large amounts of chloroform or ethyl acetate, then mixed with TEGDGE and dried before curing.

The curing reaction between the hydroxyl and epoxy groups was followed by ${ }^{1} \mathrm{H}$-NMR spectroscopy in chloroform- $\mathrm{d}$ and interrupted when no more TEGDGE was detected in the soluble fraction of the pre-polymers. The insoluble fractions/rubbers were separated using a chloroform solution then dried and thermally characterised by DSC. The glass transition temperatures $\left(T_{g}\right)$ of the pre-polymers was generally $\sim 15^{\circ} \mathrm{C}$ higher than the $\mathrm{T}_{\mathrm{g}}$ measured after curing.

1. Curing polytetramethylene ether glycol (P1), linear polypropylene glycol (P2) and perfluoropolyether (P3) with TEGDGE

When samples P1, P2 and P3 were reacted with TEGDGE in the presence or absence of the three catalysts, only chain extension was observed, with the formation of soluble polymeric materials in chloroform. These pre-polymers were therefore omitted from subsequent experiments.

2. Curing of polybutadiene (P4-P6) and epoxidised polybutadiene $(P 8, P 9)$ with TEGDGE

The polybutadiene sample P6 formed a rubbery threedimensional structure when cured with TEGDGE, whereas samples P4 and P5 produced soluble dense fluids under the same experimental conditions. The different behaviour of these three structurally-similar polybutadiene pre-polymers during curing was initially attributed to the variable proportion of epoxy groups distributed along the main chain [22]. We therefore assumed that the epoxy groups were involved in the cross-linking process, resulting in a three-dimensional structure. However, the two epoxidised polybutadiene samples (P8 and P9, 3.5 and 2.2 meq $\mathrm{g}^{-1}$ epoxy groups respectively) produced viscous fluids when reacted with TEGDGE, which disagrees with this hypothesis. 
Scandium trifluoromethanesulfonate $(1 \% \mathrm{w} / \mathrm{w})$, 2-ethylimidazole $(0.1 \% \mathrm{w} / \mathrm{w})$ and tributylamine $(0.1 \% \mathrm{w} / \mathrm{w})$ were used to accelerate the curing reaction between polybutadiene sample $\mathrm{P} 6$ and TEGDGE. The gelation times for P6 with TEGDGE were between 2 to 4 days. Complete curing was observed from 7-10 days. Scandium trifluoromethanesulfonate $(1 \% \mathrm{w} / \mathrm{w})$ accelerated the reaction by $1-2$ days, and the rubbery product was stiffer than the samples cured without a catalyst and samples cured with 2-ethylimidazole and tributylamine. The catalyst tributylamine was found to delay the curing reaction, resulting in a darker rubbery product. All the rubbers cured from the pre-polymer P6 exhibited low $T_{g}$ values between $-75^{\circ} \mathrm{C}$ and $-73^{\circ} \mathrm{C}$, which is similar to the $\mathrm{T}_{\mathrm{g}}$ of the pre-polymer at $-76^{\circ} \mathrm{C}$.

\section{Curing old polybutadiene P6 and new polybutadiene P7 with TEGDGE}

The curing of a fresh batch of P7 with TEGDGE produced a very viscous fluid. It is worth noting that all the cross-linker was consumed in the curing process. As expected from the physical appearance of pre-polymers P6 (gel) and P7 (highly viscous fluid), the different history and storage conditions of the samples had resulted in chemical differences between these samples. Both the manufacturer's documentation and the literature [29-30] indicated that ageing increases the molecular weight and density of hydroxyl-terminated polybutadienes due to the process shown in Figure 2. A larger number of hydroxyl groups was detected, accompanied by a reduction in the number of trans and vinyl isomers in the HTPB molecule (Figure 1). This result was surprising because $\mathrm{P} 7$ was found to contain more hydroxyl groups than P6 and was expected to form a tighter three dimensional network. The side hydroxyl groups in P7 were not enough to stabilize the three-dimensional structure.
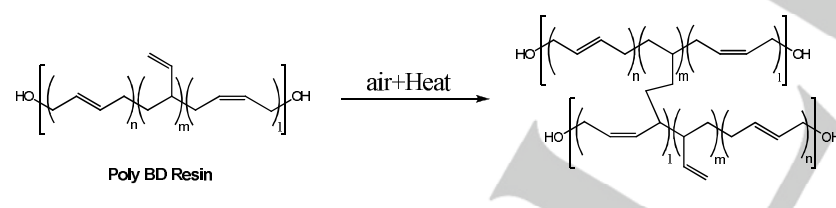

Figure 2. Self-cross-linking of the alkene groups in polybutadiene P6 (Poly BD R45HT-LO).

\section{Heat treatment of polybutadiene P4 and P7 and epoxidised polybutadiene $\mathbf{P 8}$ and $\mathbf{P 9}$ pre-polymers}

In order to confirm experimentally the above hypothesis, two polybutadiene pre-polymers (P4 and P7) and two epoxidised polybutadiene pre-polymers ( $\mathrm{P} 8$ and $\mathrm{P} 9$ ) were heat treated at $70^{\circ} \mathrm{C}$ for 14 days to encourage alkene cross-linking. To evaluate the effect of heat treatment on the molecular weight distribution and chemical modification of the pre-polymers, GPC and ${ }^{1} \mathrm{H}-\mathrm{NMR}$ analysis was undertaken on each heat-treated pre-polymer (aged) and untreated controls (unaged). The results are presented in Table 1. GPC data indicated that the molecular weights of the polybutadiene pre-polymers increased in all the aged samples with less significant changes in the epoxidised polybutadiene samples due to the lower number of unsaturated bonds. The ${ }^{1} \mathrm{H}$-NMR results showed no appreciable chemical changes in any of the heat-treated pre-polymers. Larger batches $(10 \mathrm{~g})$ of the same pre-polymers did not produce cured products when heat treated and then reacted with TEGDGE for 14 days at $70^{\circ} \mathrm{C}$. This was attributed to the limited area exposed to the air compared to small samples of the same pre-polymers [32].

Table 1. GPC results for two polybutadiene pre-polymers (P4 and P7) and two epoxidised polybutadiene pre-polymers (P8 and P9) before and after heat treatment.

\begin{tabular}{|c|c|c|c|c|c|c|c|}
\hline Sample & $\begin{array}{l}\text { Chemical } \\
\text { composition }\end{array}$ & $\begin{array}{l}\text { Trade } \\
\text { name }\end{array}$ & $\begin{array}{c}\text { Aged } \\
{[\mathrm{a}]}\end{array}$ & $\begin{array}{l}\mathbf{R T} \\
{[\mathrm{b}]}\end{array}$ & Mn & $M_{w}$ & $\begin{array}{l}\text { PD } \\
{[c]}\end{array}$ \\
\hline$\overline{P 4}$ & Polybutadiene & HTPB [d] & $\mathrm{N}$ & 15.5 & 4015 & 15972 & 4.0 \\
\hline P4 & Polybutadiene & $\begin{array}{l}\text { HTPB [d] } \\
\text { (R45M) }\end{array}$ & $Y$ & 15.5 & 6097 & 58320 & $\begin{array}{l}9.62 \\
9\end{array}$ \\
\hline P7 & Polybutadiene & $\begin{array}{l}\text { HTPB [d] (Poly } \\
\text { BD R45HT-LO) }\end{array}$ & $N$ & 15.4 & 5031 & 15006 & 3.0 \\
\hline P7 & Polybutadiene & $\begin{array}{l}\text { HTPB [d] (Poly } \\
\text { BD R45HT-LO) }\end{array}$ & $Y$ & 15.4 & 8284 & 54710 & 6.6 \\
\hline P8 & $\begin{array}{l}\text { Epoxidised [e] } \\
\text { Polybutadiene }\end{array}$ & $\begin{array}{l}\text { Cray Valley } \\
605 \mathrm{E}\end{array}$ & $\mathrm{N}$ & 16.2 & 2550 & 8727 & 3.4 \\
\hline P8 & $\begin{array}{l}\text { Epoxidised [e] } \\
\text { Polybutadiene }\end{array}$ & $\begin{array}{l}\text { Cray Valley } \\
605 \mathrm{E}\end{array}$ & Y & 16.1 & 3059 & 9684 & 3.2 \\
\hline P9 & $\begin{array}{l}\text { Epoxidised [f] } \\
\text { Polybutadiene }\end{array}$ & $\begin{array}{l}\text { Cray Valley } \\
700 E\end{array}$ & $\mathrm{~N}$ & 15.5 & 5002 & 15825 & 3.2 \\
\hline P9 & $\begin{array}{l}\text { Epoxidised [f] } \\
\text { polybutadiene }\end{array}$ & $\begin{array}{l}\text { Cray Valley } \\
700 E\end{array}$ & Y & 15.4 & 6059 & 18110 & 3.0 \\
\hline
\end{tabular}

[a] At $70^{\circ} \mathrm{C}$ for 14 days. [b] Minutes. [c] Polydispersity. [d] Hydroxyl-terminated polybutadiene. [e] 3.5 epoxy meq $\mathrm{g}^{-1}$. [f] 2.2 epoxy meq $\mathrm{g}^{-1}$.

\section{Curing heat-treated polybutadiene P4 and P7 and epoxidised polybutadiene P8 and P9 with TEGDGE}

Curing the heat-treated polybutadiene samples P4 and P7 with TEGDGE at a 1:3.5 $(\mathrm{w} / \mathrm{w})$ ratio produced gels after 2 days at $70^{\circ} \mathrm{C}$, which turned into dark orange elastomeric rubbers within 5 days (Supplementary Figure S6). The same process applied to the heat-treated epoxidised polybutadiene samples P9 and P10 resulted in the formation of a dense fluid. The viscosity of all heattreated samples increased during curing. The cured heat-treated P4 and P7 samples were characterised by DSC. A double glass temperature transition was observed between $-53^{\circ} \mathrm{C}$ and $-76^{\circ} \mathrm{C}$, which suggests that two distinct regions with dissimilar thermal behaviour co-exist in the same network. The observed double glass temperature transition is under further investigation. 


\section{Curing of acrylic ester (Hytemp) 4454) P10 with} TEGDGE

A large amount of ethyl acetate $\left(50 \mathrm{ml} \mathrm{g}^{-1}\right.$ polymer) was required to dissolve pre-polymer $\mathrm{P} 10$ before curing with TEGDGE at $70^{\circ} \mathrm{C}$ both in the presence and absence of $0.1 \% \mathrm{w} / \mathrm{w}$ scandium trifluoromethanesulfonate as a curing accelerator. The curing process was monitored by solubility testing and ${ }^{1} \mathrm{H}$-NMR analysis. The cross-linking mixtures produced rubbers after 3 days with $T_{9}$ values of 20 to $35^{\circ} \mathrm{C}$ lower than the $T_{g}$ value of uncured prepolymer P10 $\left(-42^{\circ} \mathrm{C}\right)$. Traces of unreacted TEGDGE were detected by ${ }^{1} \mathrm{H}$-NMR spectroscopy in the soluble fraction of the curing mixture after 17-22 days. This indicated that the rate of TEGDGE consumption was lower than that observed with the polybutadiene samples (P4-P9), where there was no evidence of any TEGDGE remaining in the soluble fraction after curing. The ratio of $P 10: T E G D G E$ may be too high, which might hinder the mobility of TEGDGE during curing and causing it to be trapped in the three-dimensional network despite the availability of reactive cure-sites in the polymer. Larger amounts of TEGDGE in the curing mixture resulted in shiny, film-like products, whereas smaller amounts resulted in harder, rubbery materials more closely related to the product formed when the pre-polymer P10 was heated to $70^{\circ} \mathrm{C}$ for the same duration as the other samples.

$T_{g}$ values were measured by applying DSC to the insoluble fractions remaining in the cured $\mathrm{P} 10$ mixtures that were free from unreacted TEDGDE. Double glass temperature transitions were detected at -66 and $-48^{\circ} \mathrm{C}$ as observed for the cured polybutadiene samples P4 and P7 and confirmed by other techniques but not discussed in this paper (Supplementary Figure S9) The cross-linked products began to melt at approximately $300^{\circ} \mathrm{C}$ before decomposing. The decomposition temperature of the cross-linked product increased from $345^{\circ} \mathrm{C}$ to $395^{\circ} \mathrm{C}$.

The chemical structure of the polyacrylic ester pre-polymer (P10) comprises long alkyl side chains with side carboxylic acid groups. The latter may also be involved in the cross-linking reaction, where they may promote (in cooperation with the long ethylene glycol chains of TEGDGE) the formation of two distinct crystalline and amorphous regions within the elastomeric matrix [30,31], thus forming a semi-crystalline polymer [33]. Curing of the polybutadiene (P6) and polyacrylic ester (P10) pre-polymers with 1,4-butanediol diglycidyl ether, a cross-linker that is "shorter" than TEGDGE, showed that both P6 and P10 networks are characterised by a single $T_{g}$. These data prompted the next stage of the investigation: the pre-polymers were formulated with energetic fillers such as PETN (nitrate ester) and RDX (nitramine) and cured in the presence of TEGDGE.

\section{Compatibility tests using the uncured P10 and P6 mixtures} with TEGDGE and energetic compounds (RDX and PETN)

A selection of small-scale compatibility tests (hazard testing and thermal stability testing) [31,34] were conducted on 20-mg samples of the formulations comprising the uncured pre-polymers (P6 and P10), cross-linker TEGDGE and energetic molecules
RDX or PETN. Four formulations were prepared as summarized in Table 2.

Table 2. Descriptions of the formulations used for the compatibility studies with

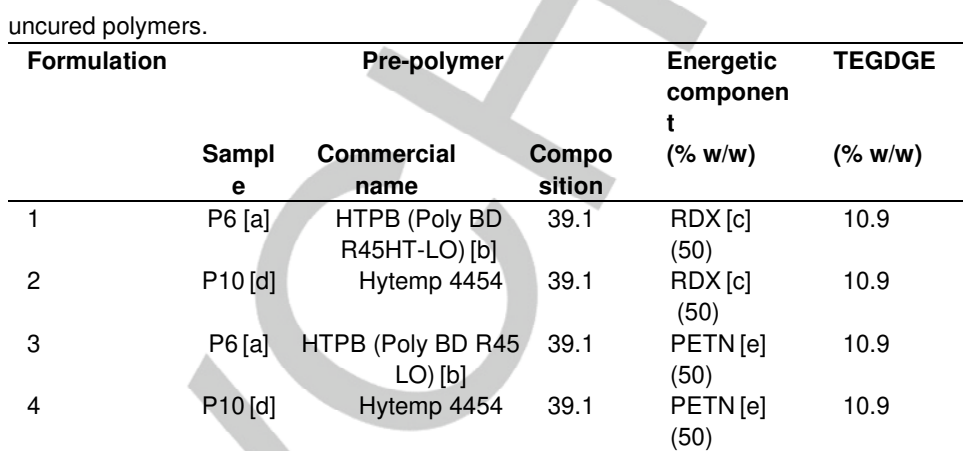

[a] Polybutadiene. [b] New sample. [c] Cyclotrimethylenetrinitramine. [d] Polyacrylic ester. [e] Pentaerythritoltetranitrate

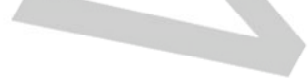

\section{Colour change}

The colour of all formulations remained the same during the mixing process. We placed $2-3 \mathrm{mg}$ of each composition (fresh sample) directly on the surface of a hot plate and heated them at $100^{\circ} \mathrm{C}$ for $30 \mathrm{~min}$. No colour change was observed for compositions P6/TEGDGE/RDX (1) and P10/TEGDGE/RDX (2) (Table 3). A pale green colour was observed for compositions P6/TEGDGE/PETN (3) and P10/TEGDGE/PETN (4), which was slightly deeper than the original composition at room temperature. A third fresh sample of each composition was left exposed to air at ambient temperature for $24 \mathrm{~h}$ and no colour changed was observed.

Table 3. Small-scale compatibility tests results.

\begin{tabular}{|c|c|c|c|}
\hline \multirow[t]{2}{*}{ Formulation } & \multicolumn{3}{|c|}{ Colour change } \\
\hline & On mixing & After $30 \mathrm{~min}$ at $100^{\circ} \mathrm{C}$ & After $24 \mathrm{~h}$ \\
\hline $1[\mathrm{a}]$ & pass & pass & pass \\
\hline $2[\mathrm{a}]$ & pass & pass & pass \\
\hline $3[\mathrm{~b}]$ & pass & $\operatorname{Tbr}[c]$ & pass \\
\hline $4[\mathrm{~b}]$ & pass & $\operatorname{Tbr}[\mathrm{c}]$ & pass \\
\hline
\end{tabular}

\section{Ignition in flame}

Formulations 1 and 2 ignited when exposed to a naked flame but did not self-sustain when the flame was removed. Some pulsation was observed as RDX particles ignited. Compositions 3 and 4 burnt readily and self-sustained. They both fizzed slightly but did not flare. A black residue representing the burnt binder was observed in both cases.

\section{Hammer and anvil - direct blow}

A small amount of each formulation (2-3 mg) was placed directly on a hard surface and struck with a small steel/wooden hammer. None of the formulations initiated after 10 hits.

\section{Hammer and anvil - glancing blow}


A small amount of each formulation (2-3 mg) was placed directly on a hard surface and was then smeared with a steel/wooden hammer. None of the compositions initiated after 10 glancing blows.

\section{Decomposition}

The results of the initial compatibility tests did not reveal any major reactions between the uncured pre-polymers and the energetic components, except the DSC analysis of formulations containing RDX (Table 4). The maximum decomposition peak was approximately $50^{\circ} \mathrm{C}$ lower than that of the pure energetic component, indicating that a reaction occurs due to the incompatibility between the RDX and one or more of the other components of the formulation, uncured pre-polymer and/or TEGDGE, as described in NATO STANAG standards [35].

Table 4. Compatibility of the energetic formulations with RDX and PETN.

\begin{tabular}{llll}
\hline Formulation & $\begin{array}{l}\text { Energetic } \\
\text { Decomposition } \\
/{ }^{\circ} \mathbf{C}\end{array}$ & $\begin{array}{l}\text { Composition } \\
\text { Decomposition } \\
/{ }^{\circ} \mathbf{C}\end{array}$ & Difference $/{ }^{\circ} \mathbf{C}$ \\
\hline 1 & 243.25 & 195.64 & -47.61 \\
2 & 243.25 & 190.59 & -52.66 \\
3 & 185.16 & 179.48 & -5.68 \\
4 & 185.16 & 180.87 & -4.29 \\
\hline
\end{tabular}

As stated in STANAG 4147 [35], '... where the admixtures decomposition temperature is between $4^{\circ} \mathrm{C}$ and $20^{\circ} \mathrm{C}$ below that of the explosive, other suitable compatibility tests should be conducted, or kinetics calculated for confirmation of compatibility...', thus the compatibility of the pre-polymer and/or TEGDGE with RDX is inconclusive and requires further investigation.

The RDX/TEGDGE, P6/RDX and P10/RDX 50:50 w/w mixtures were therefore analysed by DSC to determine their compatibility in accordance with STANAG 4147 . A peak shift of $21.85^{\circ} \mathrm{C}$ was observed for the RDX/TEGDGE mixture compared to pure RDX, but no significant difference was observed for either the P6/RDX or P10/RDX compared to pure RDX. These DSC data indicated that the incompatibility between RDX and the P6/TEGDGE and P10/TEGDGE mixtures is due to TEGDGE. These results would normally lead to the abandonment of any further formulation work, but small-scale formulations were nevertheless tested out as discussed below. The DSC results indicated no significant incompatibility for uncured mixtures 3 and 4 as determined from the temperature of ignition results presented in Table 5 and smallscale formulation work was therefore conducted as discussed below.

\section{Hazard tests of P6/TEGDGE and P10/TEGDGE filled with} energetic compounds (RDX and PETN) [31]

Samples $(10 \mathrm{~g})$ of four formulations (Table 5) are prepared and their appearance is shown in Figure 3. Prior to curing at $70^{\circ} \mathrm{C}^{1}$, formulations 5-8 were split into two $5 \mathrm{~g}$ batches, one of which was cured and the other used for hazard tests [31] without curing.

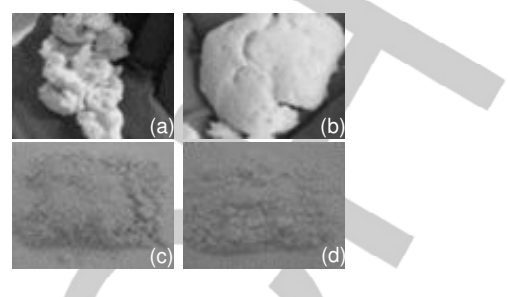

Figure 3. Pre-curing energetic formulations (a) 5, (b) 6, (c) 7 and (d) 8.

Table 5. Details of formulations used for the hazard testing Formulation Pre-polymer [a] Energetic [b] Cross-linker [c]

\begin{tabular}{|c|c|c|c|}
\hline $5[\mathrm{~d}]$ & P6 & $\mathrm{RDX}[\mathrm{e}]$ & TEGDGE \\
\hline $6[\mathrm{~d}]$ & P10 & RDX [e] & TEGDGE \\
\hline 7 [d] & $P 6$ [f] & PETN [g] & TEGDGE \\
\hline $8[\mathrm{~d}]$ & P10 & PETN [g] & TEGDGE \\
\hline
\end{tabular}

Buring processing, the physical characteristics of the energetics were found to affect the viscosity of the mixtures (Figure 3). Mixtures 7 and 8 , containing the smaller PETN particles, formed finer powders on mixing than mixtures 5 and 6 (less viscous) which contained larger RDX particles. In contrast, mixtures 6 and 8 containing pre-polymer P10 (HyTemp 4454) were doughy (very viscous) and less homogenous than mixtures 5 and 7 containing the pre-polymer P6 (Poly BD R45HT-LO). All formulations underwent a significant colour change during curing, turning golden after 11 days, which is a characteristic of the resins when cured. However, the RDX-based compositions (5.11 and 6.11) underwent a greater colour change than the PETN-based samples (7.11 and 8.11), suggesting that the colour change may be indicative of incompatibility.

After 11 days of curing, the four formulations were treated with chloroform- $d$ and the soluble fractions were characterised by ${ }^{1} \mathrm{H}$ NMR spectroscopy. The spectra revealed the soluble energetic components (RDX and PETN) and traces of unreacted TEGDGE (3.6 ppm) which confirmed the completion of the curing reaction. Table 6 lists the results of the hazard tests carried out on the samples before curing (5-8) and after 11 days of curing (5.118.11). Because the amount of the prepared formulations was not sufficient to conduct full hazard characterization according to EMTAP Manual [31] specifications, we carried out abbreviated versions of the impact (Langlie-based method), electrostatic discharge (ESD), mallet friction steel/steel and temperature of ignition tests. The results of these preliminary tests indicated that

${ }^{1}$ It is expected that the pot-life for the system at room temperature in the dark should be greater than one year. 
the cured polymer does not have any significant effect on the hazard properties of the energetic materials.

Table 6. Hazard test results for the samples (5-8) before curing and 11 days after curing [a].

\begin{tabular}{lllllllll}
\hline \multicolumn{7}{c}{ Sample } \\
\hline Test & $\mathbf{5}[\mathrm{b}]$ & $\mathbf{5}[\mathrm{b}]$ & $\mathbf{6}[\mathrm{c}]$ & $\mathbf{6}[\mathrm{c}]$ & $\mathbf{7}[\mathrm{d}]$ & $\mathbf{7}[\mathrm{d}]$ & $\mathbf{8}[\mathrm{e}]$ & $\mathbf{8}[\mathrm{e}]$ \\
\hline Time (days) & 0 & 11 & 0 & 11 & 0 & 11 & 0 & 11
\end{tabular}

\begin{tabular}{lllllllll} 
Test & $\mathbf{5}[\mathrm{b}]$ & $\mathbf{5}[\mathrm{b}]$ & $\mathbf{6}[\mathrm{C}]$ & $\mathbf{6}[\mathrm{c}]$ & $\mathbf{7}[\mathrm{d}]$ & $\mathbf{7}[\mathrm{d}]$ & $\mathbf{8}[\mathrm{e}]$ & $\mathbf{8}[\mathrm{e}]$ \\
\hline Time (days) & 0 & 11 & 0 & 11 & 0 & 11 & 0 & 11 \\
\hline $\begin{array}{l}\text { Impact by drop- } \\
\text { weight input (cm) }\end{array}$ & 102.8 & 90.9 & 107.5 & 76.7 & 40.0 & 74.9 & 64.5 & 60.4 \\
\end{tabular}
[f]

$\begin{array}{lllllllll}\text { ESD [g] } 4.5 \mathrm{~J} & 4 / 5 & 5 / 5 & 3 / 5 & 4 / 5 & 4 / 5 & 5 / 5 & 5 / 5 & 5 / 5\end{array}$

$\begin{array}{lllllllll}\text { ESD [g] 0.45J } & 0 / 10 & 0 / 10 & 0 / 10 & 0 / 10 & 2 / 10 & 1 / 10 & 1 / 10 & 3 / 10\end{array}$

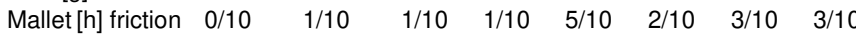

$\begin{array}{lllllllll}\text { [i] steel/steel } & 0 \% & 50 \% & 50 \% & 50 \% & 50 \% & 50 \% & 50 \% & 50 \%\end{array}$

$\begin{array}{lllllllll}\text { Temp of ignition } & 214.7 & 216.6 & 203.3 & 203.3 & 180.5 & 176.0 & 166.1 & 164.9 \\ \text { [j] }\left({ }^{\circ} \mathrm{C}\right) & 215.6 & 217.1 & 201.3 & 208.6 & 180.6 & 176.7 & 166.2 & 168.2\end{array}$ [a] At $70^{\circ} \mathrm{C}$. [b] P6/TEGDGE/RDX. [c] P10/TEGDGE/RDX

[d] P6/TEGDGE/PETN. [e] P10/TEGDGE/PETN. [f] The $5 \mathrm{~kg}$ drop-weight input test, 10 shot instead of 50 shot [28]. [g] Electrostatic discharge-positive reports on five firings at $0.45 \mathrm{~J}$ and 10 at $4.5 \mathrm{~J}$ instead of 50 tests at $4.5 \mathrm{~J}, 50$ tests at $0.45 \mathrm{~J}$ and 50 tests at $0.045 \mathrm{~J}$. [h] Ten tests instead of 100. [i] Two tests instead of 50 . [j] Temperature of ignition $\left(\mathrm{RDX}=243.25^{\circ} \mathrm{C}, \mathrm{PETN}=185.16^{\circ} \mathrm{C}\right)$

\section{Impact by drop-weight input test [31]}

To investigate the shock sensitiveness of the energetic formulations, a Langlie-based method was applied because only 10 impacts were required for each formulation (standard deviation 0-04-0.33). The reported figure of insentiveness (Fol) [28] of pure RDX is 80 , whereas the Fol of pure PETN is 50 . Therefore PETN is more sensitive to impact than RDX.

Uncured 5 and 6 formulations based on RDX showed Fol values of 102.8 and 107.5 , respectively, whereas the Fol values for the stiffer cured samples 5.11 and 6.11 were 90.9 and 76.7, respectively (Table 6 ). These Fol values were higher than those of the PETN-based formulations 7, 7.11, 8 and 8.11 (Table 6), and the latter were in turn higher than the Fol of pure PETN. The Fol value attributed to formulation 7 (40) was significantly lower than that of PETN, and this is probably an artefact of poor mixing. The Fol value of formulation 7.11 is high (74.9) and probably reflects the low density of pre-polymer $\mathrm{P} 10$, resulting in the volumetric proportion $(\mathrm{v} / \mathrm{v})$ of the formulation being higher than the proportion by mass $(5 \% \mathrm{w} / \mathrm{w})$.

\section{Electrostatic discharge (ESD) test [31]}

The results of the ESD test showed that the formulations initiated violently at $4.5 \mathrm{~J}$ but tended not to initiate at $0.45 \mathrm{~J}$, although some PETN-based samples did initiate at this energy level. No appreciable difference was observed between the cured and uncured formulations. A slight trend towards an increase in sensitiveness was observed but this trend was not statistically significant. A substantially larger sample size would be required to generate statistically significant data.

\section{Mallet friction test [31]}

A steel-on-steel mallet friction test method was applied by performing 10 serials of five glancing blows. Based on the EMTAP Manual of Tests, 0 reports (initiations) gives a score of $0 \%, 1-6$ reports gives a score of $50 \%$, and $7+$ reports gives a score of $100 \%$. No appreciable difference between the cured and uncured formulations was observed. As expected, the PETN formulations were significantly more sensitive to friction than formulations containing RDX, although seven of the eight tested specimens recorded a $50 \%$ score.

\section{Temperature of ignition [31]}

Two temperature of ignition tests were undertaken for each sample, and these are reported here along with the temperature difference between the ignition temperatures of the two samples. In all cases, P10-based samples exhibited an increase in temperature of ignition greater than $9.8^{\circ} \mathrm{C}$ when compared to P6based samples. The most significant finding in this test was confirmation that RDX and TEGDGE are incompatible. TEGDGE is thought to be consumed during the curing reaction, and a cured formulation would therefore contain so little residual TEGDGE the temperature of ignition would be largely unaffected. However, these data show that even in cured formulations containing only trace amounts of TEGDGE, incompatibility can still be recorded as a $23.15-37.7^{\circ} \mathrm{C}$ drop in the anticipated temperature of ignition of $\operatorname{RDX}\left(243.25^{\circ} \mathrm{C}\right)$. This indicates that TEGDGE may be acting as a catalyst or as an initiator for the decomposition of RDX, and thus confirms its unsuitability for RDX compositions. Due to the incompatibility previously observed with $\mathrm{RDX}$, this conclusion probably also applies to HMX (cyclotetramethylenetetranitramine).

\section{Conclusions}

TEGDGE, a new cross-linker, was used to cure several samples of commercially available hydroxyl-terminated pre-polymers with the aim to replace toxic isocyanates and overcome REACH restrictions. Most of the curing mixtures produced soluble polymeric materials due to chain extension, but polybutadiene and polyacrylic ester hydroxyl-terminated pre-polymers formed thermally-stable networks. Curing accelerators did not affect the curing process. Pre-aging of the polybutadiene samples encouraged the formation of ethylene bridges between the molecules of the pre-polymer, which facilitated cross-linking.

The polyacrylic ester pre-polymer cross-linked with TEGDGE produced rubbers with glass transition temperatures lower than that of the pre-polymer by up to $35^{\circ} \mathrm{C}$. The double glass transition temperature suggests the formation of a comb-like non-conventional curing system, due to the long alkyl side chains in the acrylic ester, resulting in the formation of distinct regions. Polybutadiene and polyacrylic ester pre-polymers were formulated with the energetic fillers RDX and PETN and successfully cross-linked with TEGDGE. Compatibility testing showed that TEGDGE is incompatible with the nitramine RDX but compatible with the nitro-ester PETN. The sensitiveness of the energetic filler formulated with polybutadiene and polyacrylic ester pre-polymers and TEGDGE generally improved compared to the pure energetics RDX and PETN. Energetic formulations of 
the polyacrylic ester pre-polymer with TEGDGE and PETN could also be suitable for applications in underground mining.

\section{Recommendations}

Investigation of the change of properties with time and overall ageing of the formulation is recommended. The assessment of the maximum energetic filler loading for the two different binders will be of interest in order to determine the limits of the studied formulations.

\section{Acknowledgements}

The authors thank Mr Chris Stennett (Cranfield University, UK) for his full support with the small-scale hazard tests on the energetic formulations, and Dr Peter Bolton (AWE plc) and Dr Ron Hollands (BAE System Munitions) for providing some of the polybutadiene pre-polymer samples.

Keywords: Toxic isocyanates, replacement, hydroxyl-terminated, cross-linked polymers, RDX, PETN

\section{References}

[1] C. W. Phetphaisit, J. Namahoot, J. Saengkiettiyut, J. Ruamcharoen and $P$. Ruamcharoen, Green metal organic coating from recycled PETs and modified natural rubber for the automobile industry, Progress in Organic Coatings, 2015, 86, 181-189.

[2] R. B. Turner, R. D. Jr. Priester and S. R. Burkes, Polyurethane foam with flame resistance, US 5104910 A 19920414 , Dow Chemical Co., USA, 1992.

[3] K. Dušek, Theory of network formation by additional crosslinking of polyurethanes due to biuret and allophanate formation, Polymer Bulletin, 1987, 17, 5 .

[4] K-S. Chen, Y-S. Chen, T. L. Yu and C-L. Tsai, Physical Properties of Tri-isocyanate Crosslinked Polyurethane, Journal of Polymer Research, 2002, 9, 119-128.

[5] V. Sekkar, S. Gopalakrishnan, D. K. Ambika, Studies on allophanateurethane networks based on hydroxyl terminated polybutadiene: effect of isocyanate type on the network characteristics, European Polymer Journal, 2003, 39, 1281-1290.

[6] A. G. Salmon, Bright red blood of Bhopal victims: cyanide or MIC? British Journal of Industrial Medicine, 1986, 43, 502.

[7] E. Broughton, The Bhopal disaster and its aftermath: a review Environmental health: a global access science source, 2005, 4, 6.

[8] U.S. Environmental Protection Agency. Toluene Diisocyanate (TDI) and Related Compounds Action Plan.

https://www.epa.gov/assessing-and-managing-chemicals-undertsca/toluene-diisocyanates-tdi-action-plan, Cited August 2016.

[9] D. Bello, C. A.Herrick, T. J. Smith, S. R. Woskie, R. P. Streicher, M. R. Cullen, Y. Liu and C. A. Redlich, Skin Exposure to Isocyanates: Reasons for Concern, Environmental Health Perspectives, 2007, 115, 328-335.
[10] J. E. Doe and H. D. Hoffmann, Toluene diisocyanate: an assessment of carcinogenic risk following oral and inhalation exposure, Toxicol Ind Health, 1995, 11, 13-32.

[11] P. Pradyot A Comprehensive Guide to the Hazardous Properties of Chemical Substances. P. Pradyot Ed. New Jersey, John Wiley \& Sons, 2007.

[12] REACH Regulation (EC) No 1907/2006

https://echa.europa.eu/addressing-chemicals-of

concern/restrictions/substances-restricted-underreach?p $p$ id=disslists WAR disslistsportlet\&p $p$ lifecycle $=1 \& p \quad p$

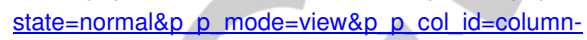
$1 \& p \mathrm{p}$ col $\mathrm{pos}=1 \& \mathrm{p} \mathrm{p}$ col count $=2 \&$ disslists WAR disslistsportle $\underline{t}$ javax.portlet.action=searchDissLists (Cited August 2017)

[13] J. E. Doe, and H. D. Hoffmann, Toluene diisocyanate: an assessment of carcinogenic risk following oral and inhalation exposure. Toxicol Ind Health. 1995, Vol. 11, 1.

[14] A. Swensson and K. Andersson, Nordiska expertgruppen for gransvarde dokumentation 58 Diiscoyanater. The Nordic Expert Group. [Online] 1985. [Cited: 1106 2013.] http://hdl.handle.net/2077/4059.

[15] J. Guan, Song, Y. Lin, X. Yin, M. Zuo, Y. Zhao, X. Tao and Q. Zheng, Progress in Study of Non-Isocyanate Polyurethane, Industrial \& Engineering Chemistry Research, 2011, 50, 6517-6527.

[16] O. L. Figovsky and L. D. Shapovalov, Features of Reaction Aminocyclocarbonate for Producation of New Type Nonisocyanate Polyurethane Coatings, Macromolecular Symposia, 2002, 187, 325332.

[17] NanoTech Industries. Green Polyurethane ${ }^{\mathrm{TM}}$. http://www.nanotechindustriesinc.com/GPU.php, Cited August 2016.

[18] S. Kar, and A. K. Banthia, Synthesis and Evaluation of Liquid AmineTerminated Polybutadiene Rubber and Its Role in Epoxy Toughening, Journal of Applied Polymer Science, 2005, 96, 2446-2453.

[19] C. Winder and A. Zarei, Incompatibilities of chemicals, Journal of Hazardous Materials, 2000, 79, 19-30.

[20] D. Falgoux, D. Simoulin and M. Pascal-Mousselard, Process for the preparation of addition products of epoxides and hydroxylated compounds, US 4543430, BP Chimie Societe Anonyme, Courbevoie, France, 1985

[21] V. C. Cunuffe, D. A. Tod, S. A. Torry, Curing method for polyether, WO 2009141593 A1, QinetiQ, UK, 2009.

[22] W. Vilar, S. Menezes and L. I. Akcelrud, Characterisation of hydroxylterminated polybutadiene. II. Determination of hydroxylated structures and a mechanistic approach for the polymerization, Polymer bulletin, 1994, 33, 563-570.

[23] P. Golding, A. J. Bellamy, A. E. Contini and E. Dossi, Polyphosphazenes, WO 2013190260 A3, The Secretary of State for Defence, UK and Cranfield University, UK, 2013.

[24] P. Golding, D. M. Duncan, A. J. Bellamy, A. E. Contini and E. Dossi, Polyphosphazenes, Patent US 9,556,314 B2, 2017

[25] R. G. Williams, Are isocyanates the best option for curing polymeric binders in PBX formulations? A new cross-linker for energetic and non-energetic binders for PBX formulations, Cranfield University, Shrivenham, UK, 2011.

[26] W.J. Doe, New PBX formulations free of toxic isocyanates, MSc Thesis, Cranfield University, Shrivenham, UK, 2012.

[27] Polyethyele glycol diglycidyl ether. http://www.sigmaaldrich.com/catalog/product/aldrich/475696?lang=e n\&region=GB, Cited October 2017.

[28] PAN Pesticides Database-Chemicals. http://www.pesticideinfo.org/Detail Chemical.jsp?Rec Id=PC43000, Cited October 2017.

[29] A. Akbas, A. Aksoy and N. Hasirci, Effects of thermal ageing on the properties and lifetime prediction of hydroxyl-terminated polybutadiene, Polymer, 1994, 35, 2568-2572. 
[30] D. J. Nagle, M. Celina, L. Rintoul and P. M. Fredericks, Infrared microspectroscopic study of the thermo-oxidative degradation of hydroxy-terminated polybutadiene/isophorone diisocyanate polyurethane rubber, Polymer Degradation and Stability, 2007, 92, 1446-1454.

[31] DOSG, EMTAP in Energetic materials testing and assessment policy committee, Manual of Tests Ed. 3, 1-1124. Defence Ordnance Safety Group (DOSG), Abbey Wood, UK 2007. https://www.gov.uk/government/uploads/system/uploads/attachment data/file/481365/20150813-

JSP520 Pt2 Vol10 Clearances Issue4.2 Final-U.pdf (Cited August 2016).

[32] K. Tamareselvy and F. A. Rueggeberg, Dynamic mechanical analysis of two crosslinked copolymer systems, Dent Mater, 1994, 10, 290-297.

[33]R. F. Boyer, Multiple transitions in semi-crystalline polymers, Plastics \& Polymers, 1993, 41, 71-78.

[34] NATO. STANAG 4147 Edition 2.

http://standards.globalspec.com/std/735118/nato-stanag-4147 (Cited August 2016) and http://www.difesa.it/Amministrazionetrasparente/segredifesa/terrarm/ Documents/4170eeD03.pdf (Cited August 2016).

[35] G. Rotter and H. Ishida, Dynamic mechanical analysis of the glass transition: curve resolving applied to polymers Macromolecules, 1992, 25, 2170-2176. 
Entry for the Table of Contents (Please choose one layout)

Layout 1:

\section{FULL PAPER}

Text for Table of Contents

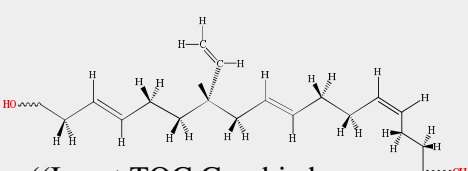

((Insert TOC Caphic here: max. width: $5.5 \mathrm{~cm}$; $\mathrm{m}$ x. height: $\$ .0(\mathrm{~cm})$ )
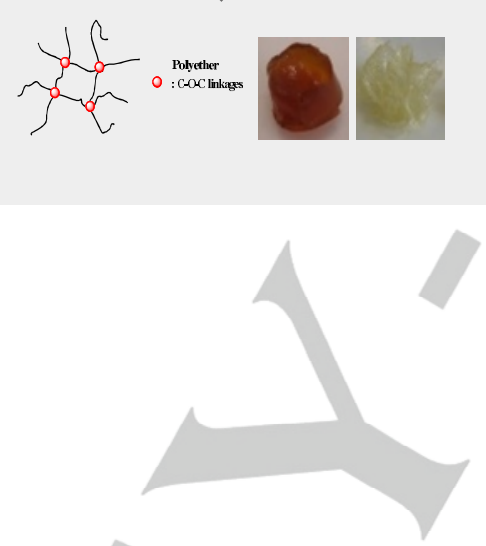

[a] Dr E. Dossi, Prof J. Akhavan, Mrs S.E. Gaulter

Centre for Defence Chemistry,

Cranfield University, Defence Academy

of United Kingdom, Shrivenham, SN6

8LA, UK

[b] Mr R.G. Williams

Royal Australian Air Force, Department of Defence, Penrith, NSW 2750, Australia

[c] Mr W.J. Doe

DE\&S, DESG Graduate Office, MoD, Abbey Wood, Bristol BS34 8JH, UK 
FULL PAPER

Additional Author information for the electronic version of the article.

Eleftheria Dossi: $\quad$ 0000-0001-6365-8019

Jackeline Akhavan: 0000-0003-0006-9203 